\title{
Measuring women's experiences of childbirth using the Birth Satisfaction Scale-Revised (BSS-R)
}

\author{
Caroline J Hollins Martin ${ }^{1}$ \\ Lucia Jimenez Martinez ${ }^{2}$
}

Colin R. Martin ${ }^{3}$
${ }^{1}$ Caroline J Hollins Martin, Professor of Maternal Health, School of Health and Social Care, Edinburgh Napier University (ENU). Email:
c.hollinsmartin@napier.ac.uk

${ }^{2}$ Lucia Jimenez Martinez, student midwife at Edinburgh Napier University (ENU). Email: 40286236@live.napier.ac.uk
${ }^{3}$ Professor Colin R. Martin, Faculty of Health Sciences, Institute for Clinical and Applied Health Research (ICAHR), Rm 329, Allam Medical Building, University of Hull, Hull, HU6 7RX, UK, Telephone: 01482463708 Email: C.R.Martin@hull.ac.uk


Caroline J Hollins Martin, Professor of Maternal Health, School of Health and Social Care, Edinburgh Napier University(ENU). Email:

c.hollinsmartin@napier.ac.uk

\title{
Measuring women's experiences of childbirth using the Birth Satisfaction Scale-Revised (BSS-R)
}

\begin{abstract}
Birth satisfaction relates to women's perceptions of their childbirth experience, which consists of personality factors, and evaluations of the quality of care provided and stress experienced. The importance of measuring 'birth satisfaction' lies in desire to improve standards of intranatal care provided, through measuring impacts of interventions (i.e., home birth versus hospital birth) and exploring relationships with other important dimensions (i.e., postnatal depression, wellbeing \& attachment). With evaluating intranatal care in mind, this paper aims to educate midwives about one particular method of measuring women's experiences of labour, which involves using the valid and reliable Birth Satisfaction Scale-Revised (BSS-R). The BSS-R is a 10-item self-report valid and reliable measure, which is recommended by the International Consortium for Health Outcomes Measurement (ICHOM) as the 'method of choice' for evaluating women's 'birth experience'. Since the ICHOM began recommending the BSS- $R$ as part of its Pregnancy and Childbirth Standard set, the scale (to date) has been used in 39 countries and 134 sites world-wide. If you would like to use the BSS-R, it can be accessed free of charge for clinical, research or educational purposes through contacting (c.hollinsmartin@napier.ac.uk).
\end{abstract}

\section{Key words:}

Childbirth, Birth experience; Birth satisfaction; Birth Satisfaction Scale-Revised; Midwives, validation 
BSS-R

\section{Key points}

(1) 'Birth satisfaction' is a retrospective evaluation of women's labour and birth experiences.

(2) The Birth Satisfaction Scale-Revised (BSS-R) is a valid and reliable tool for measuring women's levels of 'birth satisfaction'.

(3) The BSS-R is recommended by the International Consortium for Health Outcomes Measurement (ICHOM) as the 'method of choice' for evaluating women's 'birth experience'. (www.ichom.org/medical-conditions/pregnancy-and-childbirth/)

(4) Midwives can use the BSS-R to improve standards of intrapartum care in a wide range of contexts (i.e., clinical, research $\&$ education).

(5) The BSS-R has to date been used in projects based in 134 word-wide sites based in 39 countries.

(6) The BSS-R can be accessed free of charge through contacting Caroline J. Hollins Martin at (Email: c.hollinsmartin@napier.ac.uk).

\section{Declaration of interest}

The authors report no conflict of interests, with no financial support provided or accrued in relation to promoting the BSS-R. 


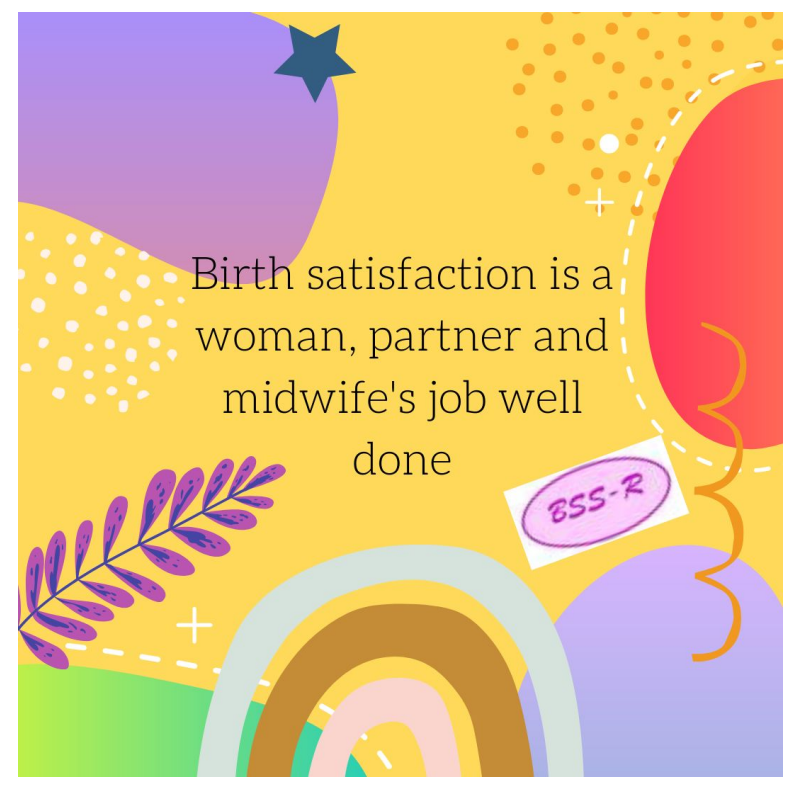

\section{Measuring women's experiences of childbirth using the Birth Satisfaction Scale-Revised (BSS-R)}

\section{Introduction}

The 10-item Birth Satisfaction Scale-Revised (BSS-R) is a multi-factorial psychometrically robust tool developed for the purpose of measuring women's experiences of labour and childbirth (Hollins Martin and Martin 2014). The $B S S-R$ is currently recommended by the International Consortium for Health Outcomes Measurement (ICHOM) as the lead international clinical tool for measuring women's experiences of labour and childbirth (Nijagal et al. 2018) (www.ichom.org/medical-conditions/pregnancy-and-childbirth/). Since the ICHOM began recommending the $B S S-R$, it has been used to measure women's 'birth satisfaction' in 39 countries and 134 sites world-wide.

\section{TABLE 1 HERE}

The BSS-R is co-owned by Caroline $\mathrm{J}$ Hollins Martin (CJHM) 
and Colin R Martin (CRM), who are both available to provide advice regarding its use. Country specific BSS-R scales are held in an electronic site based at Edinburgh Napier University (ENU), with the ICHOM directing potential users to CJHM who monitors and maintains the site. If you would like to use the $B S S-R$ free of charge for clinical or research purpose(s), please email:

\section{c.hollinsmartin@napier.ac.uk.}

\section{What is birth satisfaction?}

Birth satisfaction is defined as a retrospective maternal evaluation of labour experience (Hollins Martin et al. 2012), with reflective appraisal important because of potential impacts for mother, infant, and family wellbeing (Sawyer et al. 2013). An experience of poor 'birth satisfaction' has aptitude to effect level of mother and infant interaction (Staneva 2013) and subsequent experiences of breastfeeding (Hinic 2016). In addition, experience of a traumatic labour can increase levels of anxiety and fear surrounding planning of future pregnancies (Baxter 2020).

It is important to appreciate that every woman constructs expectations of how her childbirth experience will unfold (Staneva 2013), with individual perceptions subjective and often complex (Dannenbring et al. 1997). Literature has shown that multiple factors influence maternal experience of labour and childbirth (Hollins Martin and Fleming, 2011), with three main themes identified: (1) Quality of care provision, (2) Personal attributes, and (3) Stress experienced during labour. These three themes are now addressed.

\section{(1) Quality of care provision}


What midwives instinctively know and the literature shows, is that quality of intrapartum care provided impacts upon women's reported experiences of labour and childbirth (Hollins Martin et al. 2012). Birth satisfaction is influenced by several factors. For example, women place value upon being listened to and being placed at the centre of decision-making processes (Heatley et al. 2015; Mei et al. 2015; Miron-Shatz and Konheim-Kalkstein 2020). Quality and amount of support provided by midwives and allied health care professionals plays a vital role in level of 'birth satisfaction' reported (Luegmair et al. 2018; Dev et al. 2019; Miron-Shatz and Konheim-Kalkstein 2020), with women testifying that they feel more positive about their birth experience when their needs and comforts are considered (Luegmair et al. 2018; Hall et al. 2020).

\section{(2) Personal attributes (i.e., personality \& coping skills)}

Personality and coping skills play a significant role in shaping level of 'birth satisfaction' women report (Johnston et al. 2013; Conrad and Stricker 2018). Literature shows that women who take a proactive role to educate and prepare themselves for labour, report more positive birth experiences (Howarth et al. 2011; Hinic 2017; Miron-Shatz and Konheim-Kalkstein 2020), cope better during labour (Howarth et al. 2011), experience reduced levels of stress (Hinic 2017), and suffer less pain (McCrea and Wright 1999; Howarth et al. 2011). 'Birth satisfaction' is reported to be higher when women have choice and control in relation to methods of pain relief and style of delivery (Çalik et al. 2018; Deliktas Demirci et al. 2019). More recent research reports 
that unplanned Caesarean Section (CS) is associated with reduced 'birth satisfaction', with having an advocate for support improving experience (Konheim-Kalkstein and Miron-Shatz 2019). What is clear, is that women with high levels of 'birth satisfaction' report having felt empowered with choice and control over aspects surrounding their labour and birth (Cook and Loomis, 2012).

\section{(3) Stress experienced during labour}

Stress experienced during labour profoundly influences women's reported levels of 'birth satisfaction', with literature linking medical interventions and associated injury as one influence on reports (Çalik et al. 2018; Johansson and Finnbogadóttir 2019; Fumagalli et al. 2020; Kempe and Vikström-Bolin 2020). For example, women with intact perineum's report more positive experiences (Fumagalli et al. 2020). In relation to midwives efforts to improve 'birth satisfaction', reducing stress and its 'fight/flight' response is important. To view factors that have potential to increase level of reported 'birth satisfaction' (see Figure 1).

FIGURE 1 HERE

\section{Psychometric validation of the BSS-R}

The 10-item BSS-R is a reliable and valid tool (Hollins Martin and Martin, 2014), in response to applying robust psychometric principles. To assess factor structure, validity, and reliability of a proto 30-item BSS (Hollins Martin and Fleming 2011) and to develop a short-form version of the tool, survey 
data was collected in Scotland $(\mathrm{UK})$ from $(n=228)$ postnatal women (Hollins Martin and Martin 2015). Qualitative validation of survey data was undertaken from primary free-text data gathered from $(n=207)$ childbearing women. This data was concurrently analysed with first-hand narratives of birth satisfaction accounted for in 19 qualitative papers. From these findings, it was concluded that the initial 30-item BSS accounted for all of the underpinning qualitative data (Hollins Martin et al. 2012).

To validate a shorter version of the 30 -item BSS, factor structure and reliability was statistically assessed. Key psychometric properties of the proto 30-item BSS was evaluated using Exploratory Factor Analysis (EFA) and Structural Equation Modelling techniques (SEM) (Hollins Martin and Martin 2014). Post psychometric analysis, the 30 -item BSS was reconfigured into the 10-item BSS-R, with data confirming the three prior clustered sub-scales of quality of care provision, women's personal attributes, and stress experienced during labour (Hollins Martin and Martin 2014). Post statistical validation, the 10-item BSS-R was considered a robust tool for measuring women's 'birth satisfaction' (Hollins Martin and Martin 2014).

\section{What is the 10-item BSS-R?}

The 10-item BSS-R is comprised of 3 sub-scales which measure distinct but correlated domains of: (1) quality of care provision (4-items), (2) women's personal attributes (2-items), and (3) stress experienced during labour (4-items). To view BSS-R items (see Table 2).

\section{TABLE 2 HERE}




\section{How to score the 10-item BSS-R}

Postnatal women respond to the 10 -items on the $B S S-R$ on a 5-point Likert scale, which is based upon level of agreement or disagreement with each of the statements placed. A score of 40 represents highest possible "birth satisfaction' and 0 the lowest, with no cut-off scores. An example of how to complete Item 3 follows:

(Q3) The delivery room staff encouraged me to make decisions about how I wanted my birth to progress.

$\begin{array}{lccc}\text { Strongly } & \text { Agree } & \text { Neither Agree } & \text { Disagree Strongly } \\ \text { Agree } & \text { or Disagree } & \text { Disagree }\end{array}$

$\begin{array}{lllll}4 & 3 & 2 & 1 & 0\end{array}$

When clinicians and researchers gather data using scales, ordinarily they calculate means and significant differences between groups. For example, and in the case of the BSS-R, significant differences in mean scores between groups of primigravidas and women of multiparity, or those who have experienced CS compared with Spontaneous Vertex Delivery (SVD). In addition, the BSS-R can be used to compare group mean 'birth satisfaction' scores between women of various ages, who have received different methods of pain relief and/or have delivered at home, in a midwifery led unit, or a 
hospital. It is recommended that clinicians and researchers triangulate findings through conducting a qualitative thematic analysis of comments written by participants' under each BSS-R item, with data used to elaborate and explain cause and effect. Through analysing BSS-R survey data, areas of achievement can be acknowledged and rewarded, and conversely areas of improvement identified and where possible rectified. In response, commendations can be awarded and/or plans put in place to improve and re-measure implemented improvements or interventions.

\section{Translations and validations of the 10-item BSS-R}

Since the ICHOM started recommending the 10 -item $B S S-R$ as the measure of choice for evaluating 'birth experience' world-wide (Nijagal et al. 2018), several translations and validations of the scale have been produced for use in specified populations. In sequential order, the 10 -item $B S S-R$ has been translated and validated for use in the United States (US-BSS-R) (Fleming et al. 2016; Martin et al. 2017a), Greece (Greek-BSS-R) (Vardavaki et al. 2015), Australia (Australian-BSS-R) (Jefford et al. 2018), Turkey (Turkish-BSS-R) (Göncü Serhatlıoğlu et al. 2018), Spain (Spanish-BSS-R) (Romero-Gonzalez et al. 2019), Israel (Hebrew-BSS-R) (Skvirsky et al. 2019), Italy (Italian-BSS-R translation) (Nespoli et al. 2018), Iran (Persian-BSS-RI) (Omani-Samani et al. 2019) and Slovak (Slovak-BSS-R) (Škodová et al. 2019), with many more versions still in production. All adaptations of the 10-item BSS-R are held in an electronic site based at ENU, and are available free of charge from (c.hollinsmartin@napier.ac.uk). 


\section{Examples of 10-item BSS-R use}

A systematic review reports that the 10 -item $B S S-R$ is an easy to administer instrument for measuring women's 'birth satisfaction' (Alfaro Blazquez et al. 2017). Also and in addition to the ICHOM, the WWU Munster for medical data models recommends the 10-item BSS-R as the measure of choice in Germany (Dugas 2019). So far and to date, the 10 -item $B S S-R$ has been used in a diverse range of clinical settings. What follows are examples of some studies that have reported use of the 10-item BSS-R.

Currently the 10-item $B S S-R$ is being used in a multi-site trial in Sweden to assess women's intranatal satisfaction at 2 months post lateral episiotomy or no episiotomy (Bergendahl et al. 2019). The 10-item BSS-R has been used to evidence that women who deliver in birth centres report higher levels of 'birth satisfaction', which has had impact upon restructuring of maternity services (Breman et al. 2019). The 10-item BSS-R has been used to assess women's perceptions of quality of intrapartum care received and its effects upon anxiety, control, and stress in relation to breastfeeding (Hinic 2016). Konheim-Kalkstein and Miron-Shatz (2019) used the 6-item BSS-R Indicator (BSS-RI), which is a shortened version of the BSS-R (Martin et al. 2017b), in a study that explored impact of unplanned CS upon women's levels of reported 'birth satisfaction'. Rahimi-Kian et al. (2018) used the 10-item $B S S-R$ to test effects of ice pack application on pain and 'birth satisfaction'. Škodová et al. (2019) are currently using the 10-item BSS-R in Slovakia to explore relationships between 'birth satisfaction' and mode of delivery, socioeconomic factors, and psychological variables. Lee et al. (2018) used 
the 10-item BSS-R in Australia to assess 'birth satisfaction' in relation to two differing styles of labour management. Turnbull et al. (2019) are currently conducting a trial to identify differences between using 'CTG and ECG' versus 'CTG alone' during labour, and the overall effects on 'birth satisfaction' post emergency CS. Hamm et al. (2019) led an obstetric cohort study in the UK, which showed that black race, CS, and increasing labour length are risk factors for women reporting lower levels of 'birth satisfaction' when labour has been induced. Above are just a few examples to illustrate how midwives' can use the 10-item BSS-R in clinical practice and research.

\section{$\underline{\text { Conclusion }}$}

In summary, the 10 -item $B S S-R$ is a valid and reliable measure that can be used by clinicians and researchers to evaluate postnatal women's levels of 'birth satisfaction'. If you are considering its use, the 10 -item $B S S-R$ is available free of charge both nationally and internationally, and is recommended by the ICHOM (www.ichom.org/medical-conditions/pregnancy-and-childbirth/) as the measure of choice for assessing women's experiences of labour and childbirth. Data collected can be used to evaluate global quality of intranatal care provision, and also to identify individual successes and potential areas for improvement within clinical areas. Data collected can form baselines against which future care can be compared. Data gathered may also be correlated with findings from other validated scales (e.g., those that measure wellbeing, coping, depression etc.). CJHM and CRM continue to work with 
teams world-wide to provide advice about translation and validation of population specific versions of the 10 -item $B S S-R$, with its free availability enabling clinical and research teams to progress maternity care provision at an international level. If you would like to translate and validate a context specific 10 -item $B S S-R$, or use it to improve quality of maternity care provision, please contact us at (c.hollinsmartin@napier.ac.uk).

\section{References}


Alfaro Blazquez R, Corchon S, and Ferrer Ferrandiz E. 2017. Validity of instruments for measuring the satisfaction of a woman and her partner with care received during labour and childbirth: Systematic review. Midwifery 55: 103-12.

Baxter J. 2020. An exploration of reasons why some women may leave the birth experience with emotional distress. Br J Midwifery.

Bergendahl S, Lindberg P, and Brismar Wendel S. 2019. Operator experience affects the risk of obstetric anal sphincter injury in vacuum extraction deliveries. Acta Obstet Gynecol Scand 98: 787-94.

Breman RB, Storr CL, Paul J, et al. 2019. Women's Prenatal and Labor Experiences in a Hospital With an Early-Labor Lounge. Nurs Womens Health 23: 299-308.

Çalik KY, Karabulutlu Ö, and Yavuz C. 2018. First do no harm - Interventions during labor and maternal satisfaction: A descriptive cross-sectional study. BMC Pregnancy Childbirth 18.

Conrad M and Stricker S. 2018. Personality and labor: a retrospective study of the relationship between personality traits and birthing experiences. $J$ Reprod Infant Psychol 36: 67-80.

Cook K and Loomis C. 2012. The impact of choice and control on women's childbirth experiences. The Journal of Perinatal Education 21(3):158-168.

Dannenbring D, Stevens MJ, and House AE. 1997. Predictors of childbirth pain and maternal satisfaction. J Behav Med 20: 127-42. 
Deliktas Demirci A, Kabukcuglu K, Haugan G, and Aune I. 2019. “I want a birth without interventions": Women's childbirth experiences from Turkey. Women and Birth 32: e515-22.

Dev A, Kivland C, Faustin M, et al. 2019. Perceptions of isolation during facility births in Haiti- A qualitative study. Reprod Health 16.

Dugas M. 2019. Medical data modelshttps://medical-data-models.org/29452. Viewed 4 Mar 2020.

Fleming SE, Donovan-Batson C, Burduli E, et al. 2016. Birth Satisfaction Scale/Birth Satisfaction Scale-Revised (BSS/BSS-R): A large scale United States planned home birth and birth centre survey. Midwifery 41: $9-15$.

Fumagalli S, Colciago E, Antolini L, et al. 2020. Variables related to maternal satisfaction with intrapartum care in Northern Italy. Women and Birth.

Göncü Serhatlıoğlu S, Karahan N, Hollins Martin CJ, and Martin CR. 2018. Construct and content validity of the Turkish Birth Satisfaction Scale-Revised (T-BSS-R). J Reprod Infant Psycho/ 36: 235-45.

Hall PJ, Foster JW, Yount KM, and Jennings BM. 2020. Comfort in Labor. J Perinat Neonatal Nurs.

Hamm RF, Srinivas SK, and Levine LD. 2019. Risk factors and racial disparities related to low maternal birth satisfaction with labor induction: $A$ prospective, cohort study. BMC Pregnancy Childbirth 19.

Heatley ML, Watson B, Gallois C, and Miller YD. 2015. Women's Perceptions of Communication in Pregnancy and Childbirth: Influences on Participation and Satisfaction with Care. J Health Commun 20: 827-34. 
Hinic K. 2016. Predictors of Breastfeeding Confidence in the Early Postpartum Period. JOGNN - J Obstet Gynecol Neonatal Nurs 45: 649-60.

Hinic K. 2017. Understanding and Promoting Satisfaction in New Mothers. MCN Am J Matern Nurs 42: 210-5.

Hollins Martin CJ and Fleming V. 2011. The birth satisfaction scale. Int J Health Care Qual Assur 24: 124-35.

Hollins Martin CJ and Martin CR. 2014. Development and psychometric properties of the Birth Satisfaction Scale-Revised (BSS-R). Midwifery 30: $610-9$.

Hollins Martin CJ and Martin CR. 2015. A survey of women's birth experiences in Scotland using the Birth Satisfaction Scale (BSS). Eur J Pers Centered Healthc 3: 478.

Hollins Martin CJ, Snowden A, and Martin CR. 2012. Concurrent analysis: Validation of the domains within the Birth Satisfaction Scale. J Reprod Infant Psychol 30: 247-60.

Howarth AM, Swain N, and Treharne GJ. 2011. Taking personal responsibility for well-being increases birth satisfaction of first time mothers. $J$ Health Psychol 16: 1221-30.

Jefford E, Hollins Martin CJ, and Martin CR. 2018. Development and validation of the Australian version of the Birth Satisfaction Scale-Revised (BSS-R). J Reprod Infant Psycho/ 36: 42-58.

Johansson C and Finnbogadóttir H. 2019. First-time mothers' satisfaction with their birth experience - a cross-sectional study. Midwifery 79 . 
Johnston RG, OstMed DO, and Brown AE. 2013. Maternal trait personality and childbirth: The role of extraversion and neuroticism. Midwifery 29: $1244-50$.

Kempe $\mathrm{P}$ and Vikström-Bolin M. 2020. Women's satisfaction with the birthing experience in relation to duration of labour, obstetric interventions and mode of birth. Eur J Obstet Gynecol Reprod Biol 246: 156-9.

Konheim-Kalkstein YL and Miron-Shatz T. 2019. "If only I had..”: Regrets from women with an unplanned cesarean delivery. J Health Psychol.

Lee NJ, Neal J, Lowe NK, and Kildea S V. 2018. Comparing Different Partograph Designs for Use in Standard Labor Care: A Pilot Randomized Trial. Matern Child Health J 22: 355-63.

Luegmair K, Zenzmaier C, Oblasser C, and König-Bachmann M. 2018. Women's satisfaction with care at the birthplace in Austria: Evaluation of the Babies Born Better survey national dataset. Midwifery 59: 130-40.

Martin CR, Hollins Martin CJ, Burduli E, et al. 2017a. Measurement and structural invariance of the US version of the Birth Satisfaction Scale-Revised (BSS-R) in a large sample. Women and Birth 30: e172-8.

Martin CR, Hollins Martin C, and Redshaw M. 2017b. The Birth Satisfaction Scale-Revised Indicator (BSS-RI). BMC Pregnancy Childbirth 17.

McCrea BH and Wright ME. 1999. Satisfaction in childbirth and perceptions of personal control in pain relief during labour. J Adv Nurs 29: 877-84.

Mei JY, Afshar YR, Wong M, et al. 2015. Birth Experience Satisfaction Among 
Birth Plan Mothers [5]. Obstet Gynecol 125: 2S.

Miron-Shatz T and Konheim-Kalkstein YL. 2020. Preparedness and support, not personality, predict satisfaction in unplanned caesarean births. $J$ Obstet Gynaecol (Lahore) 40: 171-5.

Nespoli A, Colciago E, Pedroni S, et al. 2018. The birth satisfaction scale-revised (BSS-R): Process of translation and adaptation in an Italian context. Ann Ist Super Sanita 54: 340-7.

Nijagal MA, Wissig S, Stowell C, et al. 2018. Standardized outcome measures for pregnancy and childbirth, an ICHOM proposal. BMC Health Serv Res 18.

Omani-Samani R, Hollins Martin CJ, Martin CR, et al. 2019. The Birth Satisfaction Scale-Revised Indicator (BSS-RI): a validation study in Iranian mothers. J Matern Neonatal Med.

Rahimi-Kian F, Shahbazi S, Mohammadi S, and Haghani S. 2018. The effects of ice pack application on pain intensity in the active phase of labor and on birth satisfaction among primiparous women. Nurs Pract Today 5: 355-62.

Romero-Gonzalez B, Peralta-Ramirez MI, Caparros-Gonzalez RA, et al. 2019. Spanish validation and factor structure of the Birth Satisfaction Scale-Revised (BSS-R). Midwifery 70: 31-7.

Sawyer A, Ayers S, Abbott J, et al. 2013. Measures of satisfaction with care during labour and birth: A comparative review. BMC Pregnancy 
Childbirth.

Škodová Z, Nepelová Z, Grendár M, and Bašková M. 2019. Psychometric properties of the Slovak version of the Birth Satisfaction Scale (BSS) and Birth Satisfaction Scale-Revised (BSS-R). Midwifery 79.

Skvirsky V, Taubman-Ben-Ari O, Hollins Martin CJ, and Martin CR. 2019. Validation of the Hebrew Birth Satisfaction Scale-Revised (BSS-R) and its relationship to perceived traumatic labour. J Reprod Infant Psychol.

Staneva A. 2013. Childbirth in a technocratic age: the documentation of women's expectations and experiences. J Reprod Infant Psychol 31: 323-4.

Turnbull D, Salter A, Simpson B, et al. 2019. Comparing the effect of STan (cardiotocographic electronic fetal monitoring (CTG) plus analysis of the ST segment of the fetal electrocardiogram) with CTG alone on emergency caesarean section rates: Study protocol for the STan Australian Randomised contro. Trials 20.

Vardavaki Z, Hollins Martin CJ, and Martin CR. 2015. Construct and content validity of the Greek version of the Birth Satisfaction Scale (G-BSS). J Reprod Infant Psychol 33: 488-503. 


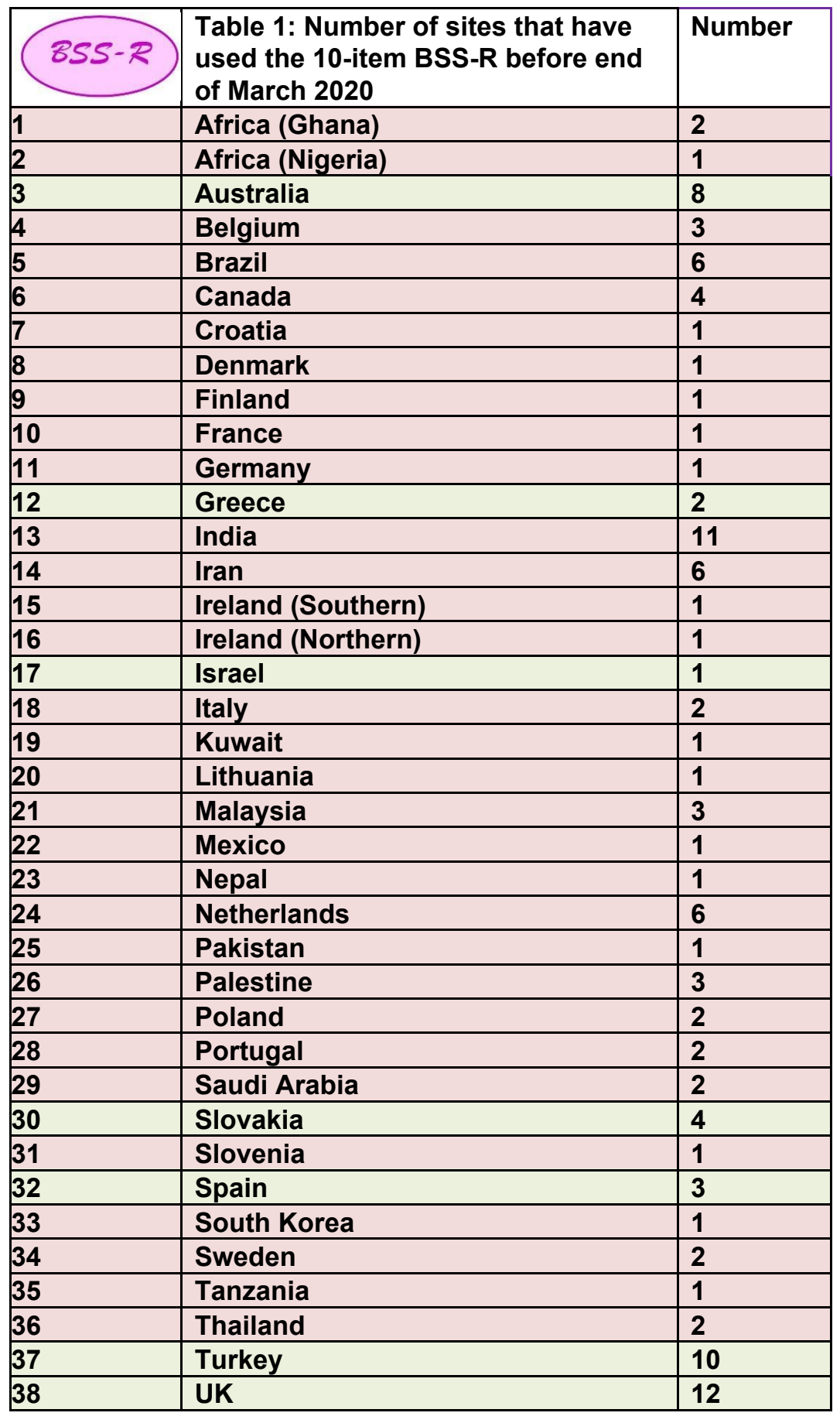




\begin{tabular}{|l|l|l|}
\hline 39 & US & 22 \\
\hline & TOTAL & 134 \\
\hline
\end{tabular}

${ }^{*}$ Green shading represents countries yet to produce validated scales

${ }^{*}$ Red represents countries with a population specific validated BSS-R

*Prof Caroline J Hollins Martin \& Prof Colin R Martin hold BSS-R ${ }^{\odot}$ copy write

Table 2: Valid and reliable 10-item Birth Satisfaction Scale-Revised (BSS-R) post psychometric statistical testing

Quality of care provision (4-items)

Women's personal attributes (2-items)

Stress experienced during labour (4-items)

(1) I came through childbirth virtually unscathed.

(2) I thought my labour was excessively long.

(3) The delivery room staff encouraged me to make decisions about how I wanted my birth to progress.

(4) I felt very anxious during my labour and birth.

(5) I felt well supported by staff during my labour and birth.

(6) The staff communicated well with me during labour.

(7) I found giving birth a distressing experience.

(8) I felt out of control during my birth experience.

(9) I was not distressed at all during labour.

(10) The delivery room was clean and hygienic.

Participants respond on a 5-point Likert scale based on level of agreement/disagreement with each of the statements placed, with a possible range of scores between $0-40$. A score of 0 on the BSS-R represents least 'birth satisfaction' and 40 most.

\author{
Strongly Agree \\ Agree \\ Neither Agree or Disagree \\ Disagree \\ Strongly Disagree
}

To obtain a copy of the 10-item BBS-R and marking grid contact Prof Caroline J Hollins Martin.

Email:chollinsmartin@napier.ac.uk

Figure 1: Factors that have potential to increase birth satisfaction 


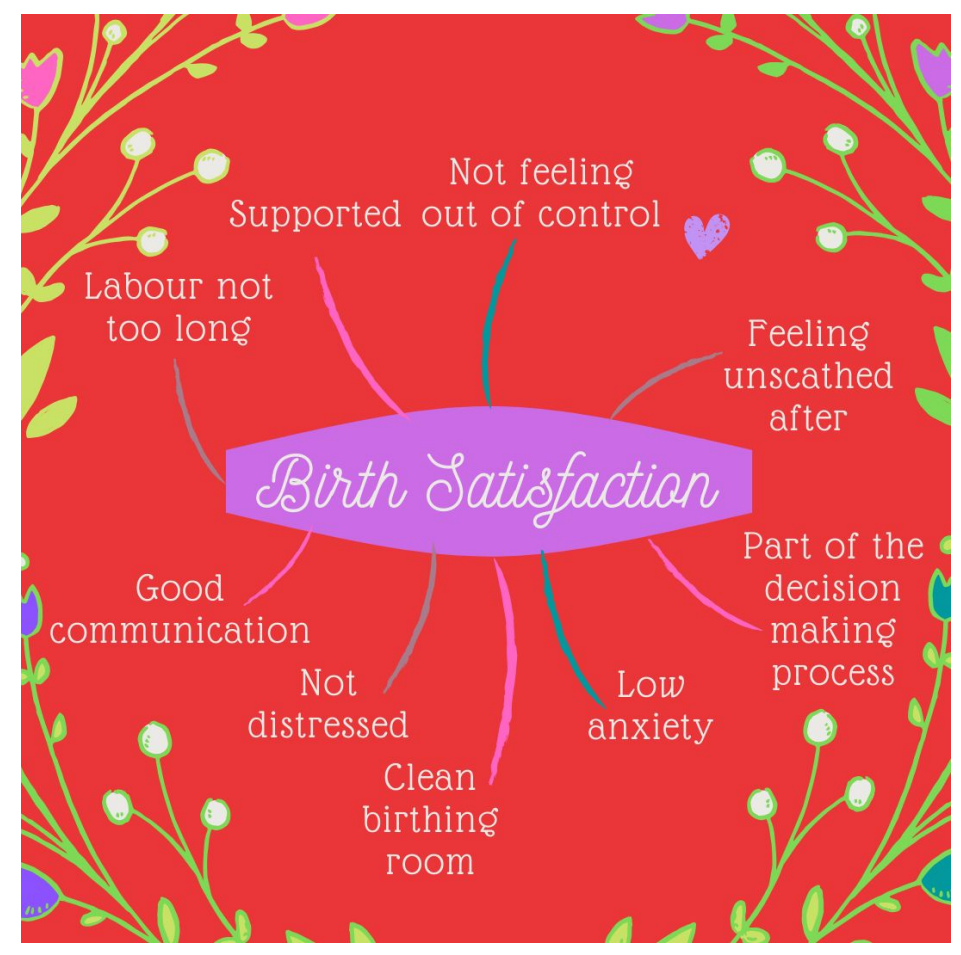

